Diabetologia (1994) 37: 111-114

Diabetologia

(C) Springer-Verlag 1994

\title{
Impact of donor-related variables on islet isolation outcome in dogs
}

\author{
M.P.M. van der Burg ${ }^{1}$, O. R. Guicherit ${ }^{1}$, M.Frölich ${ }^{2}$, J. P.Scherft ${ }^{3}$, J. A. Bruijn ${ }^{4}$, H. G. Gooszen ${ }^{1}$ \\ ${ }^{1}$ Department of Surgery, University of Leiden, Leiden, The Netherlands \\ ${ }^{2}$ Department of Clinical Chemistry, University of Leiden, Leiden, The Netherlands \\ ${ }^{3}$ Department of Cell Biology and Histology, University of Leiden, Leiden, The Netherlands \\ ${ }^{4}$ Department of Pathology, University of Leiden, Leiden, The Netherlands
}

Summary Clinical human islet transplantation programmes are considerably hampered by the variability of islet isolation outcome. The effects of the islet content of the pancreas and other donor-related variables on isolation outcome have not been evaluated systematically so far - either in large animals, or in man. We studied the impact of interindividual differences in age, body weight and pancreatic islet content on the outcome of collagenase isolation of islets from the splenic pancreas of beagle dogs $(n=31)$. The islet volume of the splenic pancreas amounted to a mean $( \pm$ SEM) $15.7 \pm 0.9 \mu$ l per gramme pancreas, and varied three-fold (from 8.4 to $27.3 \mu \mathrm{l}$ ). Isolated islet yield was $7.6 \pm 0.7 \mu \mathrm{l} / \mathrm{g}$ and varied nine-fold $(1.8-16.3 \mu \mathrm{l})$. Animals also varied in age eight-fold (8-
67 months) and body weight two-fold (8.6-18.3 kg). Differences in body weight and age explained $60 \%$ of variance in the fractional islet volume of the pancreas and $50 \%$ of the variance in islet yield $(p<0.001)$. Fractional islet volume of the splenic pancreas also explained $50 \%$ of the variance in islet yield $(p<0.001)$. We conclude that the outcome of islet isolation may be predictable after controlling for the variable islet content of pancreases, and other donor-related variables, and suggest that similar studies should be done in man. [Diabetologia (1994) 37: 111-114]

Key words Morphometry, donor, islet, isolation, pancreas, dog.
A major problem hampering large-scale human islet transplantation programmes is the variability of islet isolation outcome. Long-lasting insulin independence after allogeneic islet transplantation in Type 1 (insulindependent) diabetic patients has been achieved recently in single cases, but necessitated a variable number of donors [1]. Due to the intertwined effects of numerous variables such as predonation events, donor and pancreas characteristics, organ preservation conditions, and isolation methods, the variability of isolation outcome is difficult to analyse. Although the importance of the donor pancreas is becoming more and more appreciated, the impact of donor-related variables on isolation outcome has not been evaluated systematically so far

Received: 10 June 1993

and in revised form: 6 August 1993

Corresponding author: Dr. M.P.M. van der Burg, Department of Surgery, Building 43, University Hospital, PO Box 9600, Leiden NL2300 RC, The Netherlands
[2]. Knowledge of the variability attributable to intrinsic factors such as the islet content of the individual pancreas, is an essential prerequisite for analysis of the relative importance of the many extrinsic variables, which can be controlled. Morphometry of isolated islet yield has greatly contributed in the comparison of results from different laboratories and establishing the critical islet mass for successful transplantation $[1,2]$. As yet however, no attempts have been made to extend the use of morphometry for comparison of islet yield with the islet volume of the individual pancreas. We therefore studied the impact of interindividual differences in islet content of the pancreas and other donor characteristics on isolation outcome in a dog model.

\section{Materials and methods}

Female, outbred beagles (Harlan CPB, Zeist, The Netherlands) were used for 31 consecutive islet isolations from the splenic segment of the pancreas. After a $24-h$ fast, the animals were anaes- 
thetised as described previously [3]. The splenic segment of the pancreas was mobilised, and the pancreas was divided, where it overlies the portal vein. A specimen was taken from the cut end for morphometry and insulin extraction, and an additional specimen from the opposite end of the splenic segment in nine of our dogs for extraction. The duct was cannulated with a 20 -gauge stub adapter, and the gland was removed, weighed, and perfused (flow $1 \mathrm{ml} / \mathrm{min}$ per $\mathrm{g}$ pancreas) for $5-10 \mathrm{~min}$ with $150 \mathrm{ml}$ of an ice-cold recirculating collagenase solution ( $\mathrm{pH} 7.5$ ) containing $5 \%$ (weight/volume) Pentastarch (DCC-607; Du Pont Critical Care, Waukegan, Ill., USA), $20 \mathrm{mmol} / 1 \mathrm{HEPES}, 4.5 \mathrm{mmol} / \mathrm{l} \mathrm{so-}$ dium bicarbonate, $90 \%$ (weight/volume) of the regular Hanks' balanced salts (Flow Laboratories, Irvine, Ayrshire, UK) and 1633 U/ml collagenase (type XI; Sigma, St. Louis, Mo., USA). The gland was immersed in the remaining collagenase solution on ice, and within $40 \mathrm{~min}$ incubated at $38^{\circ} \mathrm{C}$ for $20 \mathrm{~min}$ in a water bath. The collagenase solution was decanted, and the tissue was dispersed in ice-cold University of Wisconsin solution (ViaSpan; Du Pont Pharmaceuticals, Wilmington, Del., USA) by gentle aspiration and flush through a 14-gauge needle, and filtration through a $400-\mu \mathrm{m}$ steel mesh. Trapped tissue was syringed and sieved again 1-2 times, and the final trapped tissue, which largely consisted of ductal and vascular fragments, was discarded. The islet suspension was centrifuged at $200 \times g$ and $4^{\circ} \mathrm{C}$ for $2 \mathrm{~min}$, sediments were pooled and resuspended, and aliquots were taken for islet sizing.

Pancreatic biopsy specimens were fixed in Bouin's solution and embedded in paraplast. Ten serial sections ( $5 \mu \mathrm{m}$ thick) taken at $150-\mu \mathrm{m}$ intervals were stained with haematoxylin-eosin for measurement of the islet volume fraction with the grid method for point-counting [4]. At least 40,000 points (mean: $116,250 \pm 9917$ ) per specimen were examined (relative standard error $<5 \%$ ), using a 400 -point lattice grid at $\times 200$ final magnification on systematically chosen non-overlapping fields that covered the tissue section, with exclusion of the capsular and interlobular area. The islet volume fraction was calculated from the ratio of the sum of points falling on islet profiles in the sections of the specimen, and the total number of points examined. The absolute volume of islets in the fresh pancreas was calculated by multiplying the fractional islet volume by the wet weight of the gland - assuming a density for pancreatic tissue of $1.000 \mathrm{~g} / \mathrm{ml}$. No allowance was made for shrinkage of tissue during histological processing, because - assuming isotropic, uniform shrinkage for islet and non-islet pancreatic tissue $[4,5]-$ the volume fractions are unaffected by processing. For insulin assay, approximately $40 \mathrm{mg}$ pancreatic specimens were homogenised (PT10; Polytron, Lucerne, Switzerland) and extracted overnight

Table 1. Effects of body weight and age on fractional islet volume of the pancreas and isolated islet yield $(n=31)$ by multiple correlation $(r)$ and regression $\left(b^{\prime}\right)$ analysis ${ }^{\mathrm{a}}$

\begin{tabular}{llcc}
\hline Donor & $\begin{array}{l}\text { Regression } \\
\text { indicators }\end{array}$ & \multicolumn{2}{c}{$\begin{array}{l}\text { Islet volume per gramme } \\
\text { pancreas }\end{array}$} \\
\cline { 3 - 4 } & & Pancreas & Isolated islets \\
\hline Body weight & $b^{\prime}{ }_{w}$ & $0.72^{\mathrm{b}}$ & $0.62^{\mathrm{c}}$ \\
Age & $b^{\prime}{ }_{\mathrm{a}}$ & $-0.71^{\mathrm{b}}$ & $-0.67^{\circ}$ \\
Body weight and & $r$ & $0.75^{\mathrm{b}}$ & $0.68^{\mathrm{c}}$ \\
age & $r^{2}$ & 0.57 & 0.46 \\
\hline
\end{tabular}

${ }^{a}$ Relative importance of body weight and age is indicated by beta-weights $\left(b^{\prime}\right)$ of the linear multiple regression equation: $\mathbf{U}_{\mathrm{i}}=b^{\prime} \mathrm{w} \cdot \mathbf{U}_{\mathrm{w}}+b_{\mathrm{a}}^{\prime} \cdot \mathrm{U}_{\mathrm{a}}$ with standardised units (U) of measurement for islet volume (i), body weight (w) and age (a).

${ }^{\mathrm{b}} p<0.0001,{ }^{\mathrm{c}} p<0.001$ in $1 \mathrm{ml}$ acid-alcohol $(0.15 \mathrm{~mol} / 1 \mathrm{HCl}, 77 \%$ ethanol $)$, centrifuged, and the supernatant was analysed by radioimmunoassay [3] using dog insulin as standard.

Duplicate $50-\mu$ laliquots of the islet suspensions were stained with $20 \mu \mathrm{l}$ dithizone $(0.65 \mathrm{mmol} / \mathrm{l}$ diphenylthiocarbazone and $4.5 \%$ ethanol in phosphate-buffered saline $\mathrm{pH} 7.2$, containing $\left.\mathrm{NaH}_{2} \mathrm{PO}_{4} 2.9 \mathrm{mmol} / 1, \mathrm{Na}_{2} \mathrm{HPO}_{4} 7.1 \mathrm{mmol} / 1, \mathrm{NaCl} 138 \mathrm{mmol} / \mathrm{l}\right)$ on a microscope slide. Islets were considered spheres and the mean diameters $(\geq 40 \mu \mathrm{m}$ ) were recorded in increments of $10 \mu \mathrm{m}$ using an ocular micrometer by transmission microscopy at $\times 100$ magnification, for determination of the islet volume per gramme processed pancreatic tissue $(\mu \mathrm{l} / \mathrm{g})$. A total number of $196 \pm 25$ islets, with a total islet volume of $74 \pm 11 \mathrm{nl}$, were examined. The coefficient of variation for duplicate measurements of islet volume was $17 \%$.

\section{Statistical analysis}

Results are expressed as mean \pm SEM. Differences between means were analysed by analysis of variance, and considered not significant at $p>0.05$. Linear regression and correlation was considered not significant at $p>0.01$.

\section{Results}

The insulin content at the cut end of the splenic pancreas amounted to $21.6 \pm 1.5 \mathrm{nmol} / \mathrm{g}(n=31)$ and $\mathrm{did}$ not differ from the insulin content at the opposite end of this segment, which corresponded to $107 \pm 9 \%$ of paired values in nine experiments (NS). Therefore, specimens from the cut end of the splenic pancreas were taken to represent the splenic pancreas for stereological analysis. Morphometry demonstrated a large variation of the fractional islet volume of pancreatic tissue, which averaged $1.57 \pm 0.09 \%$ and varied threefold (from 0.84 to $2.73 \%$ ). Assuming a density of $1.000 \mathrm{~g} / \mathrm{ml}$ for pancreatic tissue, islet volume per gramme pancreas amounted to $15.7 \pm 0.9 \mu \mathrm{l}$. Age of the animals was $24 \pm 2$ months and varied eight-fold (from 8 to 67 months), and body weight averaged $12.4 \pm 0.5 \mathrm{~kg}$ and varied two-fold (from 8.6 to $18.3 \mathrm{~kg}$ ). Animal weight and age were not significantly correlated $(r=0.44)$. We examined the interrelations of these variables and islet volume fraction by multiple regression and correlation analysis (Table 1): After standardising the units of measurements for age, body weight, and islet volume, we found that body weight and age had equal though opposite effects on the islet volume fraction of the pancreas. While controlling for the one variable, either body weight or age, a $100 \%$ change in the other variable was reflected by a $70 \%$ change in the islet volume per gramme pancreas. Together differences in body weight or age explained approximately $60 \%\left(r^{2}=0.57\right)$ of the interindividual differences in the islet volume fraction of the pancreas. Scattergrams illustrating these interrelations are presented in Figure 1 A, B. After collagenase digestion islet yield amounted to $7.6 \pm 0.7 \mu \mathrm{l}$ per gramme processed pancreas and varied nine-fold (from 1.8 to 

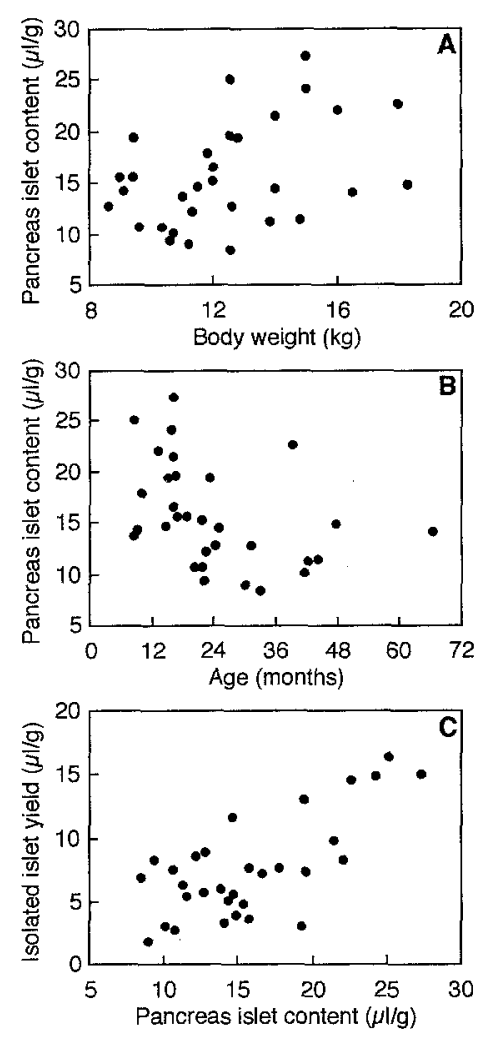

Fig. 1A-C. Scattergrams illustrating correlation between the islet content of the splenic pancreas (per gramme) and

A body weight, and B age. Multiple correlation coefficient of the combined effects of body weight and age on islet content, $r=0.75$ $(p<0.0001)$.

C Correlation of the islet content of the pancreas and isolated islet yield per gramme processed pancreas $(r=0.69, p<0.0001)$

$16.3 \mu \mathrm{l} / \mathrm{g}$ ). The effects of body weight and age on pancreatic islet content were largely reflected in islet yield, and together explained almost $50 \%\left(r^{2}=0.46\right)$ of the variance in yield. Interindividual differences in the islet content of the splenic pancreas also explained almost $50 \%\left(r^{2}=0.48\right)$ of the variance in islet yield (Fig. 1C). The efficacy of collagenase isolation - expressed as the ratio of islet yield and islet content of the pancreas - was not affected by age and body weight $\left(r^{2}=0.05\right)$.

\section{Discussion}

Little attention has been paid to the impact of the islet content of pancreases on islet yield - partly, probably, because morphometry is considered time consuming, and partly, perhaps, because little has been published on the population characteristics of islets in the pancreas of large mammals. We observed a uniform insulin distribution in the splenic pancreas. No significant regression for the fractional islet volume across the splenic half of the pancreas was also reported by Davis et al. [6] and Kroustrup and Gundersen [7] in stereological studies of the pancreas in four and eight dogs, respectively. The average islet volume fraction of $1.6 \%$ and range of $1.9 \%$ for the splenic segment in our study are similar to values of Acosta et al. [8], who obtained values of 1.6 and $2.3 \%$, respectively, from a study of 11 dogs. A mean value of $2.1 \%$ and no significant interindividual differences (range: $0.6 \%$ ) were reported by
Davis et al. [6]. However, this study was carried out with a small number of dogs. In our study $60 \%$ of the variability of the fractional islet volume of the pancreas could be attributed to the combined effects of body weight and age. The fractional islet volume increased with body weight, and decreased with age. Our data corroborate reports of a decreasing pancreatic insulin concentration with age in human infant to adult pancreases [9], and a downward trend with ageing for the fractional islet volume in adult dog pancreases [10]. The positive correlation of body weight and fractional islet volume of the pancreas in our study confirms previous findings in rodents [5]. Studies in adult rats usually report an increase of the fractional islet volume with age; however, when controlling for the increase of body weight with ageing, the fractional islet volume would probably decrease initially, and only slightly increase later with ageing [5]. The interindividual differences in pancreatic islet content as well as body weight and age explained approximately $50 \%$ of the variability of islet yield after collagenase digestion and dispersion. Several factors may have been conducive to these results. We minimised warm and cold ischaemia prior to digestion, which may adversely affect isolated islet yield [2]. By using the female laboratory beagle we further excluded variation due to sex, breed and diet. Apart from the effects of these variables [5] as well as body weight and age on pancreatic islet content, effects on the efficacy of collagenase digestion would have to be considered too. Age is a well-known variable in collagenase digestion of the pig and human pancreas [9], but not considered important in dogs. Indeed, no effects of age and body weight on isolation efficacy were demonstrated in this study. We conclude that the outcome of islet isolation may be fairly predictable after controlling for the variable islet content of pancreases, and other donor-related variables such as body weight and age. We suggest that similar studies should be done in man, which would further facilitate the analysis of other factors affecting the outcome of islet isolation for transplantation.

Acknowledgements. We thank Ms. M.G. van Schie-Troost and Ms. J.B. de Boer for providing histological preparations, Ms. K.H.Van der Nat-Van der Mey, Ms. G.M. Van Brakel, Ms. J.M.H.Heilen, Ms. H. A.M.Holtslag for skilful surgical assistance, Mr. H. Dudart, Mr. I. van Starkenburg, Mr. C. Wester for taking care of the animals, and Dr. C.J.Cornelisse for valuable advice. This work was supported by a grant from the Diabetes Research Fund, The Netherlands.

\section{References}

1. Federlin KF, Bretzel RG, Hering BJ (1992) Islet transplant registry. In: Ricordi C (ed) Pancreatic islet cell transplantation. R. G. Landes Company, Austin, pp 462-472

2. Hering BJ, Bretzel RG, Federlin K (1992) Evaluation of techniques for islet preparation and quality control. In: Hesse UJ, Pichlmaier H (eds) Islet transplantation - current status 
of clinical application and experimental results. Wolfgang Pabst Verlag, Lengerich Germany, pp 27-43

3. Gooszen HG, Van Schilfgaarde R, Van der Burg MPM, Van Lawick van Pabst WP, Frölich M, Bosman FT (1988) Quantitative assessment of long-term changes in insulin secretion after canine duct-obliterated pancreas transplantation. Transplantation 46: 793-799

4. Aherne WA, Dunnill MS (1982) Morphometry. 1 st edn. Edward Arnold, London

5. Hellman B (1959) The total volume of the pancreatic islet tissue at different ages of the rat. Acta Path Microbiol Scand 47: $35-50$

6. Davis DJ, MacAulay MA, MacDonald AS, Estabrooks BL (1988) Islets of Langerhans in dog pancreas. Transplantation 45: 1099-1103
7. Kroustrup JP, Gundersen HJG (1983) Sampling problems in an heterogeneous organ: quantitation of relative and total volume of pancreatic islets by light microscopy. J Microsc 132: $43-55$

8. Acosta JM, Buceta JC, Pons JE et al. (1969) Distribution and volume of the islets of Langerhans in the canine pancreas. Acta Physiol Latinoam 19: 175--180

9. Sutherland DER, Matas AJ, Steffes MW, Najarian JS (1976) Infant human pancreas: a potential source of islet tissue for transplantation. Diabetes 25: 1123-1128

10. Saladino CF, Getty R (1972) Quantitative study on the islets of Langerhans of the beagle as a function of age. Exp Geront 7:91-97 